\title{
Article \\ Comparable Discrimination of Soil Constituents Using Spectral Reflectance Data (400-1000 nm) Acquired with Hyperspectral Radiometry
}

\author{
Patrick J. Starks * and Ann-Marie Fortuna (D) \\ Grazingland Research Laboratory, USDA-ARS, El Reno, OK 73036, USA; Ann-Marie.Fortuna@usda.gov \\ * Correspondence: Patrick.starks@usda.gov
}

check for updates

Citation: Starks, P.J.; Fortuna, A.-M. Comparable Discrimination of Soil Constituents Using Spectral Reflectance Data (400-1000 nm) Acquired with Hyperspectral Radiometry. Soil Syst. 2021, 5, 45. https://doi.org/10.3390/ soilsystems 5030045

Academic Editor: Abdul M. Mouazen

Received: 3 May 2021

Accepted: 5 August 2021

Published: 11 August 2021

Publisher's Note: MDPI stays neutral with regard to jurisdictional claims in published maps and institutional affiliations.

Copyright: (c) 2021 by the authors. Licensee MDPI, Basel, Switzerland. This article is an open access article distributed under the terms and conditions of the Creative Commons Attribution (CC BY) license (https:// creativecommons.org/licenses/by/ $4.0 /)$.
Abstract: Currently, a gap exists in inventorying and monitoring the impact of land use and management on soil resources. Reducing the number of samples required to determine the impact of land management on soil carbon (C) and mineral constituents via proximal sensing techniques such as hyper-spectral radiometry can reduce the cost and personnel required to monitor changes in our natural resource base. Previously, we used an expensive, high signal-to-noise ratio (SNR) field spectrometer to correlate soil constituents to hyperspectral diffuse reflectance (HDR), over the 350-2500 nm (VIS-SWIR) wavelength range. This research is an extension of preceding research but focuses solely on the 400-1000 nm (VIS-NIR) region of the electromagnetic spectrum. This region can be measured using less expensive (albeit with lower SNR), miniaturized, field spectrometers that allow minimal sample preparation. Our objectives are to: (1) further evaluate the use of soil HDR in the visible and near-infrared (VIS-NIR) region acquired using an expensive field hyperspectral spectroradiometer for prediction of soil C and selected fractions and nitrogen (N) constituents, (2) repeat the above measurements using HDR data from samples examined in objective (1) using lower SNR hyperspectral radiometers, and (3) add to the limited literature that addresses determinations of selected soil properties using proximal sensing in the VIS-NIR region. Data analyzed in this study confirms that good to satisfactory prediction equations for soil constituents can be developed from spectral reflectance data within the 400-1000 nm wavelength region obtained using relatively inexpensive field radiometers. This application could reduce the time and resources required to monitor gains or losses in carbon constituents, information that can be used in programing such as Conservation Technical Assistance (CTA), the Conservation Reserve Program (CRP) and Climate-smart agriculture (CSA).

Keywords: proximal sensing; soil organic carbon; soil nitrogen; particulate organic matter; acid hydrolysis resistant carbon; visible-near-infrared spectrum

\section{Introduction}

Laboratory benchtop near-infrared spectroscopy (NIRS, $780 \mathrm{~nm}$ to $2500 \mathrm{~nm}$ ), a form of proximal sensing which typically measures hyperspectral diffuse radiation (HDR) in the UV-SWIR (300-2500 nm) portion of the electromagnetic spectrum, was evaluated early on and found to be useful in quantifying some soil properties. For example, Dalal and Henry [1] showed that NIRS could be used to develop multiple regression equations to predict soil moisture content, organic carbon (C), and total nitrogen (N). Reeves et al. [2] showed that NIRS was useful in determining total $\mathrm{C}$ and $\mathrm{N}$ in low organic matter soils, but that NIRS may or may not be useful in quantifying biomass $\mathrm{N}$, or active $\mathrm{N}$ depending upon the nature of the research question. Terhoeven-Urselmans et al. [3] demonstrated that NIRS provided good predictions of soil C:N ratios, and percentages of carbonyl, aromatic, O-alkyl, alkyl, alkyl/aromatic, and alkyl/O-alkyl C components of soil organic matter. Zornoza et al. [4] found that spectra from NIRS provided "good" predictions of water-soluble $\mathrm{C}$, and water holding capacity. 
The use of field-portable radiometers as a replacement for NIRS, or as a proxy for laboratory protocols that require additional expenditures for laboratory analytical equipment, chemicals, supplies, and personnel, will expedite analyses, reduce cost and waste as well as lead to possible in-situ measurements of soil and terrain properties. A number of investigators have investigated HDR acquired in the UV-SWIR from portable field proximal sensors for a variety of soil and geologic applications. For example, Gras et al. [5] used HDR in the UV-SWIR to successfully quantify carbonates, total N, and organic C, and Liu et al. [6] and de Paul Obade et al. [7] used it to quantify organic $C$ and total N.

Due to the importance of soil $C$ and the need for rapid and timely assessments of $C$ stocks $[8,9]$, it is not surprising that the use of proximal sensing to quantify soil $\mathrm{C}$, and its various fractions, is well represented in the literature [10-13]. Vasques, Grunwald and Sickman [10] collected VIS-SWIR (400-2500 nm) HDR spectra from 141 dried and sieved soil samples representing seven soil types and several different land uses in the Santa Fe River watershed (Florida, USA). These researchers found that the HDR data accounted for about $86 \%$ of the variability in measured total soil organic carbon (TSOC), and that 82 , 70,65 , and $40 \%$ of the measured variability in recalcitrant organic $\mathrm{C}(\mathrm{RCAH})$, hot-water soluble organic $\mathrm{C}$ (HWOC), mineralizable organic $\mathrm{C}$ (MOC), and hydroloyzable organic $\mathrm{C}$ (HOC, equivalent to RCAH in our study), respectively, was accounted for by the HDR data. Sarkhot et al. [11] collected HDR in the VIS-SWIR region for soils in a 35-ha field under two land uses. Soil cores were collected down to $50 \mathrm{~cm}$ and each core divided into five $10-\mathrm{cm}$ segments $(\mathrm{n}=514)$. The soils were dried and sieved and the HDR data collected via a portable field spectrometer. Validation statistics from the study indicated that 77 and $86 \%$ of the variability in measured HWOC and TSOC was accounted for by the proximally sensed data. Rossel and Hicks [14] investigated the use of VIS-SWIR data for prediction of TSOC, bulk density, ROC (equivalent to RCAH), and particulate and humic $\mathrm{C}$ fractions (POMC and HOC). Proximal sensing data from 141 samples of dried and sieved soils were collected via a portable field spectrometer. Their analysis indicated that TSOC and bulk density were well predicted. According to these authors, prediction equations for POMC, $\mathrm{HOC}$, and ROC/RCAH were found to have small to moderate uncertainty. All of the studies noted here used an expensive, high signal-to-noise ratio (S-N-R). Our previous research, Fortuna et al. [15], used HDR UV-SWIR data, acquired via a high S-N-R, portable field spectrometer to predict total whole and ground soil carbon (TSOC) and nitrogen (TSN), particulate soil C and N (POMC, POMN), residual C of acid hydrolysis (RCAH) in both ground and unground dried and sieved soils. Performance metrics from both the equation calibration and validation phases indicated that $>90 \%$ of the variability in each of the measured variables was accounted for by the proximally sensed data. Cursory analysis (unpublished), by the current authors, suggested that proximal sensing of soil C concentrations of soil C, $\mathrm{N}$ and mineral fractions could potentially be predicted via spectral reflectance data within the narrower VIS-NIR $(400-1000 \mathrm{~nm})$ portion of the spectrum.

Literature addressing the use of the VIS-NIR region for the quantification of soil C and its fractions is limited. Rossel and Hicks [14] stated that about one-half of the diagnostic wavelengths from the VIS-SWIR data that they used in their study to predict TSOC were located in the VIS (400-700 nm) portion of the spectrum. Stenberg et al. [16] noted that soil organic matter could have strong absorbance in the VIS due to the dominance of chromophores and due to the darkness of organic matter that may be present in the soil. Recently, Thaler et al. [17] developed a SOC index based only on HDR data collected in the VIS from 7916 soil samples collected from over 2000 locations across the United States. These authors indicated that this index yielded an RMSE of 1.3\%, which was comparable to the RMSE (1.5\%) from predictions of SOC using the SWIR/NIR ratio. It should be noted that the spectra used in the development of this index were acquired using a high-end (high SNR) spectroradiometer. Literature describing the use of the VIS and VIS-NIR region as acquired from portable, lower cost and lower S-N-R proximal sensors is also limited. Aldana-Jague et al. [18] evaluated the use of multispectral images for quantification of SOC over the Rothamsted experimental field. Images of the field were 
acquired at $480,550,670,7880$, and $880 \mathrm{~nm}( \pm 10 \mathrm{~nm})$ with a UAV-mounted camera. During calibration, equation predictions accounted for $98 \%$ of the variability in measured SOC and equation cross-validation indicated an RMSE of $0.26 \%$. Crucil et al. [19] evaluated both inexpensive multi-spectral and hyperspectral devices for application of predicting SOC under laboratory and outdoor conditions. Performances of these devices were compared to that obtained from a high-end spectroradiometer, and it was found that coefficients of determination $\left(\mathrm{r}^{2}\right)$ under laboratory conditions were $>0.93$ for all sensors, with the high-end spectroradiometer yielding a 0.96 . The $\mathrm{r}^{2} \mathrm{~s}$ were generally lower under outdoor conditions but $>0.85$.

The research reported herein is an extension of our previous work reported in Fortuna et al. [15], but correlates the same variables (TSOC, total soil N (TSN), ROC, POMC and particulate soil N (POMN) to the HDR data collected only in the VIS-NIR region of the spectrum. Our analysis also evaluates VIS-NIR HDR data acquired not only from the high-end PSR +3500 spectroradiometer, but also that from comparatively inexpensive and low S-N-R proximal (low-end) sensors. The specific objectives of this research were: (1) to further evaluate the use of soil HDR in the VIS-NIR acquired a high-end spectroradiometer, (2) collect spectral data from the same soils in (1) using less expensive and lower S-N-R hyperspectral spectroradiometers and compare results to those generated in (1).

\section{Materials and Methods}

\subsection{Soil Samples}

Details of collection and processing of the soil samples used in this study are found in Fortuna et al. [15]; therefore, only a brief summary is provided here. The soil samples were collected from three 1.6 ha sized watersheds at the USDA-ARS Grazinglands Research Laboratory, located in El Reno, OK, USA ( $\left.35^{\circ} 32^{\prime} 28^{\prime \prime} \mathrm{N}, 98^{\circ} 02^{\prime} 56.5^{\prime \prime} \mathrm{W}\right)$. Soil samples were taken from the three self-contained watersheds established in 1976 that represent southern tallgrass prairie, or winter wheat (Triticum aestivum) management. Prior to construction of the individual 1.6 ha watersheds, the site was in southern tall grass prairie. Watershed units 1 and 2 were maintained as southern tall grass prairie; primarily big bluestem (Andropogon gerardii Vitman), indiangrass [Sorghastrum nutans (L.) Nash], and little bluestem [Schizachyrium scoparium (Michx.) Nash]. Watershed unit 5 was managed under low-disturbance (no or minimal tillage), planted to winter wheat since 1976 with an additional warm season forage sorghum-sudangrass (Sorghum bicolor (L.)) in some years. Soil samples were taken from watersheds 1,2 and 5 to calibrate and validate equations developed from proximal sensor HDR data for determination of changes in total soil organic carbon (TSOC), total soil nitrogen (TSN), residual $\mathrm{C}$ of acid hydrolysis (RCAH), and particulate organic matter C (POMC) and N (POMN) [20-22].

Each watershed contained four replicate sampling stations $4.6 \mathrm{~m} \times 3.8 \mathrm{~m}$ in size at three landscape positions (tread, riser and toe slopes) representing four replicate sampling zones that captured the catena effects, slopes and aspects. Four random soil cores $0-30-\mathrm{cm}$ were taken from each sample station using a Model HDGSRPS hydraulic probe (Giddings, Windsor, CO, USA) and further divided into three depths, $0-5-\mathrm{cm}, 5-15-\mathrm{cm}$ and $15-30-\mathrm{cm}$. Four soil cores were collected from each of the four replicates at the three landscape positions in each of the watersheds and cut into three depths, yielding 144 soil cores. For each landscape position, one soil core from each of the replicates was randomly chosen and combined and composited, by depth increment $(0-5,5-15,15-30 \mathrm{~cm})$ to represent the soil conditions in a given watershed at that landscape position and depth increment ( $\mathrm{n}=108$ soil samples). Sub-samples of each soil sample were dried at $40{ }^{\circ} \mathrm{C}$ in a drying oven, after which half-gram samples of oven-dried soil, POM, and RCAH were analyzed for total TSN, TSOC, POMN, POMC, and RCAH analysis on a 928 Series LECO C/N Analyzer (Leco Corporation, St. Joseph, MI, USA) via dry combustion. 


\subsection{Hyperspectral Data Collection and Proximal Sensor Characteristics}

In this study, we employed four spectroradiometers: a Spectral Evolution PSR + 3500 (Spectral Evolution, Inc., Haverhill, MA, USA), a StellarNet EPP2000 (StellarNet Inc., Tampa, FL, USA), and Ocean Optics (Ocean Insight, Dunedin, FL, USA) STS-VIS and STS-NIR radiometers. The PSR +3500 is a high-end field portable spectroradiometer that uses three separate detectors to cover the spectral range indicated in Table 1 . The first detector is a 512element silicon diode (Si) array covering the ultraviolet and NIR (UV-NIR) 350-1000 nm region of the spectrum. Center point separation between adjacent wavelengths is $1 \mathrm{~nm}$, but detector elements are sensitive to contributions from other wavelengths as indicated by the detector's full-width-half-maximum (FWHM, Table 1). Thus, for the PSR + 3500, an HDR measurement at a center wavelength of $700 \mathrm{~nm}$ actually includes soil reflectance from 698.6-701.4 $\mathrm{nm}$. The second and third detectors are 256-element, thermo-electrically cooled InGaAs arrays covering the shortwave infrared 1 (SWIR1, 970-1910 nm), and shortwave infrared 2 (SWIR2, 1900-2500 nm) regions, respectively, but the data from these two detectors are not used in this study. Results from using the complete spectrum (UV-SWIR) and full chemometric treatment (spectral smoothing, noise reduction, and derivatives) are reported by Fortuna et al. [15]. The VIS-NIR data reported in [15] were parsed from the full UV-SWIR data for reanalysis and comparison of results from the other sensors used in this study. A minimal $\log (1 / \mathrm{R})$ transformation (where $\mathrm{R}$ is the soil reflectance at a given wavelength) of the spectral data was chosen to reflect a probable application of proximal sensing in a real-time, in-situ field setting.

Table 1. Characteristics of the spectroradiometers used in this study.

\begin{tabular}{|c|c|c|c|c|c|c|}
\hline Sensor & $\begin{array}{l}\text { Spectral Range } \\
(\mathrm{nm})\end{array}$ & $\begin{array}{c}\text { Distance } \\
\text { between } \\
\text { Wavebands }(\mathrm{nm})\end{array}$ & $\begin{array}{c}\text { Spectral Range } \\
\text { Used in This } \\
\text { Study (nm) }\end{array}$ & $\begin{array}{l}\text { Spectral Resolution } \\
\text { (nm @ FWHM) }^{1}\end{array}$ & $\begin{array}{c}\text { Signal-to-Noise } \\
\text { Ratio }\end{array}$ & $\begin{array}{l}\text { Fiber Optic } \\
\text { Field of View } \\
\text { (deg) }\end{array}$ \\
\hline PSR + 3500 & $350-2500$ & 1.0 & $400-1000$ & $\leq 2.8 @ 700$ & $>15,000: 1$ & 25 \\
\hline EPP2000 & 195.0-1100.5 & 0.50 & 436-1000 & 10.0 & $<2000: 1$ & 11 \\
\hline STS-VIS & $335.286-821.946$ & 0.48 & $435-822$ & 1.5 & $>1500: 1$ & 15 \\
\hline STS-NIR & $632.482-1122.341$ & 0.48 & $632-1000$ & 1.5 & $>1500: 1$ & 15 \\
\hline
\end{tabular}

${ }^{1}$ Full-width-half-maximum (FWHM).

The EPP2000 used in this study consists of one 2048-element Si diode array detector and is characterized by a $0.5 \mathrm{~nm}$ separation between adjacent wavebands (Table 1). The FWHM is about 3.5 times larger than that of the PSR + 3500 and 6.7 times larger than that of the STS devices; thus, reflectance in each EPP2000 waveband had contributions from more regions of the spectrum than that for the other sensors. The S-N-R is about an order of magnitude lower than that of the PSR + 3500, but similar to that of the STS sensors. The EPP2000 measures reflectance in the 195.0-1100.5 nm range, but only the VIS-NIR portion is used in this study. Further, the spectral data from this device where exceptionally noisy below $436 \mathrm{~nm}$; thus, HDR data below this value were eliminated from analysis. The remaining HDR data were transformed in the same manner as that indicated for the PSR +3500 .

The STS-VIS and STS-NIR are miniaturized radiometers, each with a small footprint $(40 \times 42 \times 24 \mathrm{~mm})$ and weight $\sim 60 \mathrm{~g}$. Although the STS-VIS and STS-NIR devices cover different spectral ranges (Table 1), they exhibit similar features in terms of spectral resolution which is about one-half that of the PSR +3500 's first detector. Spectra from the STS-VIS sensor were noisy below $435 \mathrm{~nm}$ and were removed from analysis. Spectra from the STS-NIR sensor above $1000 \mathrm{~nm}$ were removed from analysis as they were outside the VIS-NIR region used in this study. The HDR data collected with these devices were transformed in the same manner as described for PSR +3500 . A fiber optic cable was attached to the entrance port of each spectroradiometer for collection of the HDR of samples. Due to the types of optics and accessories specific to each spectroradiometer, the experimental apparatus used for illuminating the soil samples and the subsequent capture of the spectra varied between devices. 


\subsection{1. $\mathrm{PSR}+3500$}

One end of a fiber optic probe was attached to the spectroradiometer and the other to a contact probe with an integrated illuminating lamp. The contact probe was mounted on a tripod to maintain a consistent distance $(\sim 1.5 \mathrm{~cm})$ and view angle $\left(\sim 8^{\circ}\right.$ from vertical $)$ with respect to the samples being scanned.

Samples were packed into black circular cups (inside diameter of $\sim 2 \mathrm{~cm}$ ) and scanned three times. A white reference panel (Labsphere Inc., North Sutton, NH, USA) scan was acquired prior to every six experimental samples. Reflectance factors $(R)$ were calculated using the internal spectrometer software in which each sample scan was divided by the most recent reference panel scan. The $\mathrm{R}$ data were downloaded and the three scans for a given sample were averaged and converted to pseudo-absorbance by calculating the log $(1 / R)$. The resulting averaged scan for a given sample was then paired with the appropriate laboratory measurement of TSOC, TSN, POMC, POMN, or RCAH.

\subsubsection{EPP2000 and STS Devices}

The viewing end of the fiber optics for these devices were attached to a lab stand and were held at $\sim 5 \mathrm{~cm}$ from the soil sample and at $\sim 45^{\circ}$ angle to the down-welling light provided by an overhead halogen mug lamp located approximately $50 \mathrm{~cm}$ above the soil sample. The distance and view angle were chosen in such a way as to avoid casting a shadow from the apparatus onto the sample. Due to the increased viewing angle, with respect to that of the PSR +3500 , we increased the soil surface area to be viewed by placing the soil samples in a flat-black painted aluminum weigh boat having an internal diameter of $\sim 5 \mathrm{~cm}$. Each soil sample was scanned three times and $\mathrm{R}$ spectra calculated by the software in the same way as described for the PSR +3500 . The $\mathrm{R}$ spectra for a given sample were averaged and associated with the appropriate TSOC, TSN, POMC, POMN, and RCAH data for analysis.

To match the spectral distance between adjacent wavelength peaks of the PSR +3500 $(1 \mathrm{~nm}$ ), the wavelengths of the EPP2000 and STS devices (each having $\sim 0.5 \mathrm{~nm}$ distances between adjacent wavelengths, Table 1) were rounded to the nearest $1 \mathrm{~nm}$. The procedure generally produced two "replicate" HDR measurements at a given wavelength. These replicates were averaged to produce $R$ spectra having a $1 \mathrm{~nm}$ separation. The $R$ data were then converted to $\log (1 / R)$ values as described above.

\subsection{Calibration and Statistical Analysis of Spectroradiometry Data}

The $\log (1 / \mathrm{R})$ VIS-NIR data sets from the PSR + 3500, STS, and EPP2000 spectrometers were analyzed using partial least squares (PLS) regression in JMP 14 Pro (SAS Institute, Cary, NC, USA). Prior to analysis, and within the JMP software, each device-specific data set was randomly divided into a calibration subset (consisting of $70 \%$ of the data set) and a validation subset (the remaining $30 \%$ ). The data sets were analyzed for outliers using plotting features within the software, including statistical distance, normal quantile by residual, and Hotelling's $\mathrm{T}^{2}$. The final number of samples after the removal of outliers, is reported within the tables containing the calibration and validation results. Objective functions used to assess the performance of the calibration equations and their validation consisted of the ratio of the standard deviation to the RMSE for the calibration data set (RPDc) or ratio of the standard deviation for the validation data set (RPDv), slope, RMSE, and $\mathrm{r}^{2}$. We calculated RPDc according to Bellon-Maurel et al. [23]:

$$
\operatorname{RPD}_{\mathrm{c} \text { or } \mathrm{v}}=\frac{\mathrm{SD}_{\mathrm{c} \text { or } \mathrm{v}}}{\operatorname{RMSE}_{\mathrm{c} \text { or } \mathrm{v}}\left(\frac{\mathrm{n}}{\mathrm{n}-1}\right)^{0.5}}
$$

where SD = standard deviation. In Equation (1), the subscript $\mathrm{c}$ or $\mathrm{v}$ indicates whether the calibration or validation data subsets were used in the calculation. Further, we used the RMSE of the PSR + 3500 as a reference against which we compared RMSEs from the other proximal sensor dataset. Based on the guidance provided in Chang et al. [24] and 
Ludwig et al. [25], a good prediction equation is one that has a $\mathrm{r}^{2}>0.9$, a slope between 0.9 and 1.1, inclusive, a RPD $>2$, whereas a satisfactory prediction equation should a $\mathrm{r}^{2} \geq 0.64$, a slope between 0.8 and 1.2, inclusive, and a RPD between 1.4 and 2.0, inclusive.

\section{Results}

\section{1. $P S R+3500$ Calibration Performance}

The values of the objective functions used to evaluate the performance of the calibration equations are given in Table 2 . For the PSR $+3500, \geq 91 \%$ of the variation of the measured data within each soil constituent data set was explained by the HDR data. The slope of the equations for each soil constituent was 1 and all RPDc were $\geq 3.4$, indicating that all the PSR + 3500 calibration equations performed at the good level. In comparison to the other proximal sensors, the PSR +3500 produced the lowest RMSEs for TSN and RCAH only; however, the PSR + 3500, STS-NIR and STS-VIS + NIR provided comparable RMSEs for POMN.

Table 2. Calibration and validation statistics for each device and soil constituent. RMSE = root mean square error, $\mathrm{r}^{2}=$ coefficient of determination, RPD is the ratio of the standard deviation to the standard error of calibration (C) or standard error of prediction $(\mathrm{V})$, and $\mathrm{n}$ is the number of samples.

\begin{tabular}{|c|c|c|c|c|c|c|c|c|c|c|c|}
\hline \multicolumn{7}{|c|}{ Calibration } & \multicolumn{5}{|c|}{ Validation } \\
\hline Device & Slope & RMSE & $r^{2}$ & RPDc & $\mathrm{n}$ & & Slope & RMSE & $\mathrm{r}^{2}$ & RPDv & $\mathbf{n}$ \\
\hline & & & & & & $\begin{array}{c}\text { TSN } \\
\left(\mathrm{g} \mathrm{kg}^{-1}\right)\end{array}$ & & & & & \\
\hline PSR + 3500 & 1 & 0.14 & 0.94 & 4.3 & 76 & & 0.96 & 0.23 & 0.88 & 2.0 & 23 \\
\hline ЕРP2000 & 1 & 0.24 & 0.83 & 2.1 & 59 & & 1.17 & 0.21 & 0.89 & 2.3 & 20 \\
\hline STS-VIS & 1 & 0.20 & 0.88 & 2.6 & 64 & & 1.14 & 0.29 & 0.79 & 1.4 & 18 \\
\hline STS-NIR & 1 & 0.27 & 0.84 & 1.9 & 61 & & 1.15 & 0.24 & 0.82 & 1.7 & 21 \\
\hline \multirow[t]{2}{*}{ STS-VIS + NIR } & 1 & 0.35 & 0.64 & 1.3 & 60 & & 0.84 & 0.20 & 0.83 & 2.4 & 27 \\
\hline & & & & & & $\begin{array}{c}\text { TSOC } \\
\left(\mathrm{g} \mathrm{kg}^{-1}\right)\end{array}$ & & & & & \\
\hline PSR + 3500 & 1 & 2.11 & 0.90 & 3.4 & 76 & & 0.94 & 2.83 & 0.86 & 1.8 & 23 \\
\hline EPP2000 & 1 & 2.77 & 0.83 & 2.1 & 59 & & 1.14 & 2.45 & 0.89 & 2.3 & 20 \\
\hline STS-VIS & 1 & 3.51 & 0.73 & 1.6 & 64 & & 0.81 & 2.90 & 0.75 & 2.0 & 21 \\
\hline STS-NIR & 1 & 2.42 & 0.89 & 2.8 & 63 & & 1.1 & 2.67 & 0.87 & 2.3 & 22 \\
\hline \multirow[t]{2}{*}{ STS-VIS + NIR } & 1 & 1.80 & 0.93 & 3.5 & 64 & & 1.45 & 3.61 & 0.75 & 1.2 & 23 \\
\hline & & & & & & $\begin{array}{c}\mathrm{POMN} \\
\left(\mathrm{mg} \mathrm{kg}^{-1}\right)\end{array}$ & & & & & \\
\hline PSR + 3500 & 1 & 46.23 & 0.91 & 4.1 & 70 & & 0.95 & 47.33 & 0.89 & 3.2 & 23 \\
\hline EPP2000 & 1 & 64.17 & 0.83 & 2.2 & 41 & & 0.92 & 56.33 & 0.85 & 2.7 & 11 \\
\hline STS-VIS & 1 & 53.24 & 0.85 & 2.5 & 50 & & 1.18 & 62.70 & 0.84 & 1.7 & 19 \\
\hline STS-NIR & 1 & 45.65 & 0.91 & 3.0 & 50 & & 0.81 & 78.34 & 0.65 & 1.9 & 20 \\
\hline \multirow[t]{2}{*}{ STS-VIS + NIR } & 1 & 44.71 & 0.92 & 3.5 & 60 & & 0.96 & 68.82 & 0.75 & 2.0 & 20 \\
\hline & & & & & & $\begin{array}{l}\text { POMC } \\
\left(\mathrm{g} \mathrm{kg}^{-1}\right)\end{array}$ & & & & & \\
\hline PSR + 3500 & 1 & 0.74 & 0.92 & 4.4 & 70 & & 0.90 & 0.92 & 0.84 & 2.8 & 23 \\
\hline EPP2000 & 1 & 1.16 & 0.80 & 2.1 & 41 & & 0.91 & 0.96 & 0.81 & 2.7 & 11 \\
\hline STS-VIS & 1 & 0.88 & 0.84 & 2.3 & 54 & & 0.92 & 0.51 & 0.93 & 3.8 & 15 \\
\hline STS-NIR & 1 & 0.36 & 0.96 & 6.6 & 56 & & 1.15 & 1.07 & 0.81 & 2.0 & 19 \\
\hline \multirow[t]{2}{*}{ STS-VIS + NIR } & 1 & 0.48 & 0.97 & 5.2 & 60 & & 0.79 & 0.96 & 0.82 & 2.3 & 20 \\
\hline & & & & & & $\begin{array}{c}\mathrm{RCAH} \\
\left(\mathrm{g} \mathrm{kg}^{-1}\right)\end{array}$ & & & & & \\
\hline PSR + 3500 & 1 & 1.09 & 0.95 & 4.4 & 71 & & 1.07 & 1.57 & 0.93 & 3.2 & 20 \\
\hline EPP2000 & 1 & 1.65 & 0.92 & 3.3 & 52 & & 0.77 & 1.77 & 0.86 & 2.9 & 13 \\
\hline STS-VIS & 1 & 1.38 & 0.93 & 3.8 & 47 & & 1.04 & 1.42 & 0.94 & 3.6 & 13 \\
\hline STS-NIR & 1 & 1.26 & 0.94 & 3.8 & 44 & & 1.03 & 2.08 & 0.88 & 2.4 & 13 \\
\hline STS-VIS + NIR & 1 & 1.62 & 0.91 & 3.1 & 45 & & 0.95 & 1.14 & 0.93 & 4.4 & 14 \\
\hline
\end{tabular}


With the possible exception of POMC, the EPP2000 calibration equations also performed at the good level (all slopes $=1, \mathrm{r}^{2}>0.81$, and RPDc $\geq 2.0$ ). Two of the three objective functions for POMC fell within the "good" category; however, the $\mathrm{r}^{2}$ value for POMC was 0.80 resulting in the overall classification of satisfactory. The RMSE values of the EPP2000 equations were from 1.3 to 1.6 times larger than observed for the corresponding PSR +3500 equations.

The STS-VIS HDR data produced equations that performed at the good level for all soil constituents, except TSOC which performed at the satisfactory level $\left(\mathrm{r}^{2}=0.73\right.$, RPDc $=1.6$ ). The RMSEs of the calibration equations were generally higher (ranging from 1.2 to 1.7 times larger than observed for the corresponding PSR + 3500 equations.

The STS-NIR HDR data produced a satisfactory equation for TSN and good equations for all other soil constituents. Although the slope and $\mathrm{r}^{2}$-values for TSN indicated a good equation, the RPDC $=1.9$, which is just lower than the recommended value for a good equation. The POMN and POMC RMSEs were comparable to and lower than, respectively, those observed for the PSR + 3500 equations. The remaining RMSEs were from 1.2 to 1.6 times higher than observed for the corresponding PSR +3500 equations.

Except for the TSN equation, all equations produced from the STS-VIS + NIR (composited) HDR data were classified as good, and yielded RPDc $\geq 3.1$. The TSN equation fell just under the satisfactory category due to a low RPDc value (1.3) and its RMSE was 2.5 times larger than observed for the corresponding PSR + 3500 equation. The RMSEs for TSOC, POMN, and POMC were 15, 3, and 35\% lower and the RMSE for RCAH was 1.5 times larger than observed for the corresponding PSR +3500 equations.

The composited data provided better performance for TSOC and POMN than did the STS-VIS and STS-NIR data when used separately. Correlograms of STS composited reflectance data for each soil constituents contained unique diagnostic absorptions (Figure 1). All STS-based equations were classified as good for RCAH, with the STS-VIS and STS-NIR equations having slightly higher $\mathrm{r}^{2}$ and much higher RPDc values. Similarly, all STS-based equations performed at the good level for POMN, with the the STS-NIR and STS-VIS + NIR HDR data accounting for $>90 \%$ of the variability in the measured data, while the STS-VIS sensor accounted for $85 \%$. The RPDc values $\geq 3.0$ for STS-NIR and STS-VIS + NIR, and 2.5 for the STS-VIS. For POMC, the STS-NIR and STS-VIS + NIR performed comparably: both equations accounted for $\geq 96 \%$ of the variability in the measured data and RPDc $>5.0$. The STS-VIS HDR data also produced a good equation for POMC, accounting for $84 \%$ of the variability in the measured data and yielding a RPDc or 2.3. The STS-NIR and STS-VIS + NIR data produced good equations for TSOC, accounting for 89 and $93 \%$ of the variability in the measured data, respectively. When used on its own, STS-VIS accounted for $73 \%$ of the variability in TSOC and yielded a RPDc of 1.6; resulting in a satisfactory calibration equation.

\section{2. $P S R+3500$, EPP2000, and STS Validation Performance}

When applied to the validation datasets, the predictive equations developed from the PSR +3500 data were classified as good for all soil constituents, except TSOC. Both the slope and $\mathrm{r}^{2}$-values were within the bounds of a good validation, but the RPDv $=1.8$ of this data set forced the equation for TSOC into the satisfactory class. All RPDv were $\geq 2.0$ for all other soil constituents.

The predictive equations developed from the EPP2000 data revealed good validation performance for TSOC and POMN, and satisfactory performance for TSN (large slope), POMC (small $\mathrm{r}^{2}$ ), and RCAH (small slope). The EPP2000 RMSEs were smaller and larger for TSOC and POMN, respectively, than observed for the corresponding PSR + 3500 validation equations. The EPP2000 RMSEs were lower, slightly higher, and higher than observed for their PSR + 3500 counterparts for TSN, POMC, and RCAH, respectively (Table 2). 


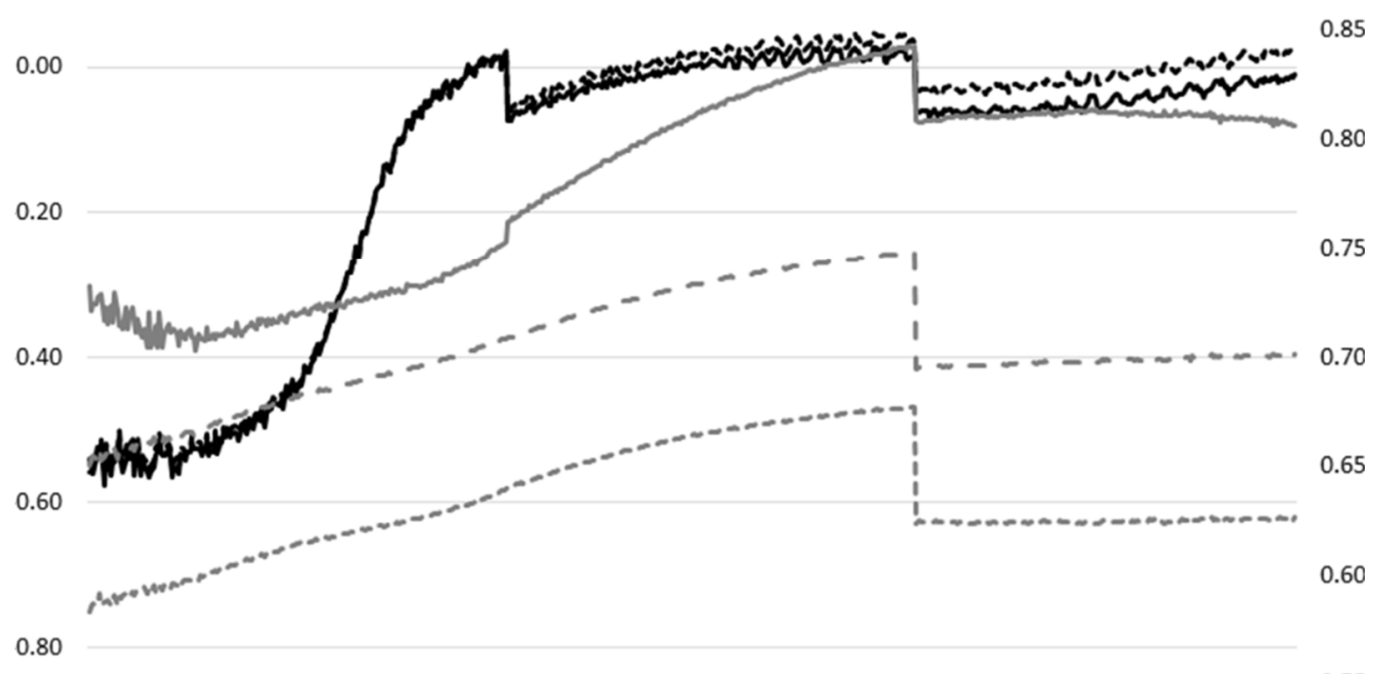

Figure 1. Correlograms of STS composited reflectance data for each soil constituents. Total soil nitrogen (N), Total soil carbon (C) and its fractions, namely particulate organic matter carbon (POMC), particulate organic matter nitrogen (POMN), and resistant (i.e., recalcitrant) organic matter C (RCAH). RCAH, POM N and POM Care plotted on a secondary vertical axis to accentuate differences. Correlogram axes correlation $(r, y$-axis) and reflectance at a wavelength ( $x$-axis).

The STS-VIS predictive equations exhibited satisfactory performance for TSN, TSOC, and POMN and good performance for POMC and RCAH. The RMSEs for TSN and POMN were 1.3 times larger and the RMSES for POMC and RCAH were 45 and 10\% smaller, respectively, than observed for the corresponding PSR + 3500 equations. The RMSEs for TSOC were similar between the STS-VIS and PSR + 3500 equations.

For the STS-NIR sensor, satisfactory predictive equations for the validation data sets were observed for TSN, POMN, and POMC. Good performance was observed for TSOC and RCAH. The TSN and TSOC RMSEs were slightly larger and slightly smaller than observed for the corresponding PSR + 3500 equations, whereas the STS-NIR RMSEs for POMN, POMC, and RCAH were about 1.7, 1.2, and 1.3 times larger than that for the corresponding PSR + 3500 equations.

The composited STS HDR data performed at the good level for RCAH and at the satisfactory level for TSN, POMN, and POMC. The respective RMSEs were 0.73, 0.87, 1.5, and 1.04 times, respectively, that of their PSR +3500 counterparts. The performance of the predictive equation for TSOC was deemed unsatisfactory due to a low RPDv and large slope. The composited HDR data performed better than the STS-VIS or STS-NIR data alone for TSN, TSOC, and POMN. However, the STS-VIS data performed better than STS-NIR or STS-VIS + NIR for POMC and RCAH.

In Fortuna et al., [15] calibration and validation results were reported for TSOC, TSN, POMN, POMC, and RCAH based on UV-SWIR (350-2500 nm) HDR data acquired with the PSR + 3500 used in the current study. The spectra used in [15] had received various mathematical transformations, noise reduction, and spectral smoothing; thus, those results provide a "baseline" against which the PSR + 3500 VIS-NIR results reported herein may be compared. The baseline results showed that all calibration models were classified as good; 
each equation explained $>92 \%$ of the variation observed in the measured data and all RPDc were $>2.8$. The validation performance of these equations also indicated good performance for all soil constituents: each equation accounted for $>90 \%$ of the variation observed in the measured data, and all RPDv $>2.6$. The calibration results obtained herein indicated that all equations using the PSR +3500 VIS-NIR data provide good performance: all $\mathrm{r}^{2} \geq 0.9$ and all RPD $\geq 3.4$, and all but the TSOC equation had RPD $\geq 2.0$, but all validation $\mathrm{r}^{2}$ indicated that from 84 to $93 \%$ of the variation was accounted for in the measured data.

\section{Discussion}

Results from the calibration phase indicated that the data collected from each sensor was capable of delivering datasets that produced satisfactory to good equations, as a function of sensor or soil constituent with one exception the STS-VIS + NIR for TSN, classified as satisfactory. When the calibration (predictive) equations were applied to the validation data sets, all of the less expensive sensors accept the STS-VIS + NIR for TSOC produced at least satisfactory results. In contrast, the high-end field radiometer achieved good performance for all soil constituents. Side-by-side comparison of the STS devices indicated that the STS-VIS sensor was more effective at predicting POMN, POMC, and RCAH.

Crucil et al. [19] included an analysis using the STS-VIS and STS-NIR sensors and two multi-spectral cameras (each having four to six wavebands, all in the visible to near infrared region) for prediction of soil organic $\mathrm{C}$. They compared their results to that obtained from an ASD FieldSpec 3 (comparable to our PSR + 3500). Spectral data was collected in both the lab and field. Laboratory measurements obtained an RPD $=3.9$ and $\mathrm{r}^{2}=0.94$ for the STIS-VIS+NIR; the field obtained an RPD $=2.6$ and $\mathrm{r}^{2}=0.85$. The above authors performed mathematical transformations on the spectra before developing/validating the equations. In contrast, we obtained similar results without any transformation apart from a $\log (1 / R)$ transformation.

In the current study, calibration equations based on the PSR + 3500 VIS-NIR spectra also provided good equations; each equation accounted for $>90 \%$ of the variation in the measured data and all RPDc were $\geq 3.4$. Validation performance metrics also indicated good performance for all soil constituents except TSOC, which was classified as satisfactory $\left(r^{2}=0.86, \mathrm{RPDv}=1.8\right)$. The validation performance metrics for all soil constituents indicated that each equation accounted for $\geq 84 \%$ of the variation in the measured data and all RPDv (except for TSOC) $\geq 2$.0. Overall, the results reported herein for the PSR +3500 indicate that higher precision will likely be obtained using the UV-SWIR, but that the VIS-NIR portion of the spectrum can also provide good estimates of TSN, POMC, POMN, and RCAH, and satisfactory estimates for TSOC.

Additional absorption features associated with mineralogical features associated with the VIS range include Fe-oxide minerals such as goethite that are associated with the sand sized POM fraction absent from the RCAH fraction $[15,26]$. The STS-NIR device was better used for TSOC. Recent research comparing hyperspectral data from STS-NIR $(650-1100 \mathrm{~nm})$, STS-VIS (350-800 $\mathrm{nm})$ and ASD $(350-2500 \mathrm{~nm})$ have verified that there were 78 wavelengths that correlated with carbon in the $450-1050 \mathrm{~nm}$ range and this region could be used to measure soil carbon in-situ with the aid of laboratory calibration [19].

Whole soil contains major absorption features attributed to amides (1001 nm) lignin, starch, protein $(1288 \mathrm{~nm})$, cellulose, lignin, starch $(1361 \mathrm{~nm})$, carboxylic acids $(1443 \mathrm{~nm})$, methyls $(\mathrm{C}-\mathrm{H})(1748 \mathrm{mn})$ and amid II, protein $(2192 \mathrm{~nm})$ all within the NIRS range $(750-2500 \mathrm{~nm})[15,25]$. Combining the STS-VIS and STS-NIR data produced satisfactory performance for POMN and POMC (but not better than STS-VIS alone) and good performance for RCAH (marginally better than STS-VIS alone). RCAH contains major absorption features attributed to amines $(990 \mathrm{~nm})$, carboxylic acids $(1450 \mathrm{~nm})$ and aliphatics $(1758 \mathrm{mn})$ in the NIR region $[15,27]$. The VIS range $(350-780 \mathrm{~nm})$ includes major absorption features associated with chromophorous groups and organic pigments associated with plant residues and other organic constituents associated with POM and SOM [10,15,27]. 
Whole soil $\mathrm{N}$ and $\mathrm{C}$ absorption patterns were the most similar and overlapped with RCAH. In contrast, POM C only overlapped with $C$ and $N$ between $\sim 436-532 \mathrm{~nm}$. The correlogram for POM N did not overlap with any other constituent, but the shape of the unique diagnostic absorptions of POM C and $\mathrm{N}$ were similar. Tahler et al. [17] developed a soil carbon index using only the VIS portion of the spectrum. They used soils data and spectra obtained by NRCS (acquired using a high-end spectrometer; ASD FieldSpec). It is not indicated in the article if the spectra underwent any mathematical transformation, other than converting the digital numbers into reflectance $(\mathrm{R})$ values. The data was parsed to reflect only the VIS (400-700 nm) wavelengths. Authors reported that their SOC index had an RMSE of $1.5 \%$. This study included satellite applications. Comparisons of the accuracy of NIRS and VIS technologies to measure SOC were conducted based on the spectral regions accuracy, cost and ease of application were conducted by Viscarra-Rossel et al. [28]. The minor increase in accuracy of predicting shifts in SOC associated with the use of NIRS relative to VIS was not sufficient to justify the added cost and time required to use NIRS.

Aldana-Jague et al. [18] used multi-spectral data (six wavebands, centered on 480, $550,670,780,880,1000 \mathrm{~nm}$; all $\pm 10 \mathrm{~nm}$ ) in the VIS-NIR. Their application was to mount the sensor on a UAV so they could map soil C. They report a $R^{2}$ of 0.98 and RMSE of $0.17 \% \mathrm{C}$ for calibration, with a cross-validation of $\mathrm{R}^{2}=0.95$ and RMSE of $0.21 \% \mathrm{C}$. They also used an external validation data set and found a good fit with an RMSE $=0.26 \% \mathrm{C}$. Other researchers that have measured the $350-2500 \mathrm{~nm}$ spectrum have found similar predictive capabilities within the visible spectrum for soil $\mathrm{N}$ and $\mathrm{N}$ at $400-480 \mathrm{~nm}, 640-700 \mathrm{~nm}$, $418 \mathrm{~nm}, 470 \mathrm{~nm}, 760 \mathrm{~nm}$, and ferrous and ferric iron oxides at $400 \mathrm{~nm}, 450 \mathrm{~nm}, 510 \mathrm{~nm}$, $550 \mathrm{~nm}, 700 \mathrm{~nm}, 870 \mathrm{~nm}$ and $1000 \mathrm{~nm}$ across a range of Oxisols in Madagascar. Use of the visible spectrum to monitor soil carbon constituents has been scaled up to regional, national and global scales via efforts such as the NRCS Soils2026 initiative [29,30] and for implementing global policies that foster Sustainable Development Goals. The application of portable field -based active and passive remote and spectroradiometers proximal sensors to measure soil properties is a growing area of research and is a natural progression to expedite further the measurement of soil properties. Visible and near-infrared reflectance spectroscopy (VNIR, 350-2500 nm), the study of light of the visible and near-infrared reflected from material surfaces, is a quick, cost-efficient, and nondestructive technique in soil sciences [31]. A number of agencies and organizations are involved in creating and maintaining soil spectral libraries to predict soil properties [32-34]. United States Department of Agriculture (USDA) initiatives that inventory and assess the impact of land use and management on soil resources are limited by a lack of site-specific information and scope of measurements required to aggregate and interpret natural resource databases at regional, national and global scales [29,35]. The current Natural Resources Conservation Service (NRCS) digital mapping of dynamic soil properties to quantify soil landscapes and properties to enhance conservation planning is also limited by the number of measurements required to complete the Soils2026 initiative $[30,36]$. Therefore, a gap exists with respect to radiometry methods (measures of electromagnetic radiation that include the visible and near infrared spectrum of light) that can be used to evaluate changes in soil properties resulting from the effects of implementing conservation practices as well as measure, manage and implement policies that utilize and enhance natural resources [30,37]. Edaphic indicators currently employed as traditional measures of soil fertility $(C, N)$ analyzed by soil testing laboratories for fertilizer recommendations can be estimated using radiometry techniques [38]. Development of new cultivars and the introduction of specialty crops also require the revision and development of soil fertility recommendations to reflect more accurately current and future markets along with soil types. Additional incentives include the need for methods that increase throughput, reduce cost, and minimize chemical waste. These requirements have spurred researchers to evaluate proximal sensing as a more convenient and efficient way to quantify important physical, chemical and biological soil properties. 


\section{Conclusions}

Currently, a gap exists in inventorying, monitoring, parameterizing, and validating the impact of land use and management on soil resources. Radiometry techniques and applications has the potential to expedite measurements of soil carbon and mineral constituents in a timelier, cost-efficient, and possibly, in-situ manner. We confirmed that hyperspectral diffuse reflectance data in the 400-1000 $\mathrm{nm}$ region of the electromagnetic spectrum can be used to develop good prediction equations that can be used to estimate of TSOC, TSN, POMN, POMC, and RCAH relative to results acquired using the full spectrum $(350-2500 \mathrm{~nm})$ that received full chemometric/manipulations with relatively inexpensive radiometers. The use of such spectrometers will facilitate application of in-situ field research, and increase the timeliness of results, reduce laboratory chemical wastes, reduce costs, and increase sample analysis throughput. The ability to predict soil $\mathrm{C}$ fractions with fewer direct chemometric measures coupled with the added benefit of light weight, small inexpensive sensors in the $350-1000 \mathrm{~nm}$ range to be integrated into unmanned aerial vehicles (UAV) units will enable researchers to monitor larger areas for shifts in carbon with land use/management.

Author Contributions: Conceptualization, P.J.S. and A.-M.F.; P.J.S. and A.-M.F. methodology; software, P.J.S.; validation, P.J.S.; formal analysis, P.J.S.; data curation, P.J.S. and A.-M.F.; P.J.S. and A.-M.F. wrote the manuscript; P.J.S. and A.-M.F. edited the manuscript and contributed their intellectual property. All authors have read and agreed to the published version of the manuscript.

Funding: This research is a contribution from the Long-Term Agroecosystem Research (LTAR) network. LTAR is supported by the United States Department of Agriculture.

Institutional Review Board Statement: Not applicable.

Informed Consent Statement: Not applicable.

Data Availability Statement: The data presented in this study are available on request.

Acknowledgments: This research contributed to the Conservation Effects Assessment Project and is a contribution of the USDA-ARS Southern Plains Long-Term Agroecosystem Research Site.

Conflicts of Interest: The authors declare no conflict of interest.

Disclaimers: Mention of trade names or commercial products in this publication is solely for the purpose of providing specific information and does not imply recommendation or endorsement by the US Department of Agriculture. The US Department of Agriculture (USDA) prohibits discrimination in all its programs and activities on the basis of race, color, national origin, age, disability, and where applicable, sex, marital status, familial status, parental status, religion, sexual orientation, genetic information, political beliefs, reprisal, or because all or part of an individual's income is derived from any public assistance program. USDA is an equal opportunity provider and employer.

\section{References}

1. Dalal, R.C.; Henry, R.J. Simultaneous determination of moisture, organic carbon, and total nitrogen by near infrared reflectance spectrophotometry. Soil Sci. Soc. Am. J. 1986, 50, 120-123. [CrossRef]

2. Reeves, J.B.; McCarty, G.W.; Meisinger, J.J. Near infrared reflectance spectroscopy for the analysis of agricultural soils. J. Near Infrared Spectrosc. 1999, 7, 179-193. [CrossRef]

3. Terhoeven-Urselmans, T.; Michel, K.; Helfrich, M.; Flessa, H.; Ludwig, B. Near-infrared spectroscopy can predict the composition of organic matter in soil and litter. J. Plant Nutr. Soil Sci. 2006, 169, 168-174. [CrossRef]

4. Zornoza, R.; Guerrero, C.; Mataix-Solera, J.; Scow, K.M.; Arcenegui, V.; Mataix-Beneyto, J. Near infrared spectroscopy for determination of various physical, chemical and biochemical properties in Mediterranean soils. Soil Biol. Biochem. 2008, 40, 1923-1930. [CrossRef] [PubMed]

5. Gras, J.P.; Barthès, B.G.; Mahaut, B.; Trupin, S. Best practices for obtaining and processing field visible and near infrared (VNIR) spectra of topsoils. Geoderma 2014, 214, 126-134. [CrossRef]

6. Liu, Y.; Jiang, Q.; Fei, T.; Wang, J.; Shi, T.; Guo, K.; Li, X.; Chen, Y. Transferability of a visible and near-infrared model for soil organic matter estimation in riparian landscapes. Remote Sens. 2014, 6, 4305-4322. [CrossRef]

7. De Paul Obade, V.; Lal, R.; Moore, R. Assessing the accuracy of soil and water quality characterization using remote sensing. Water Resour. Manag. 2014, 28, 5091-5109. [CrossRef]

8. Issa, S.; Dahy, B.; Ksiksi, T.; Saleous, N. A review of terrestrial carbon assessment methods using geo-spatial technologies with emphasis on arid lands. Remote Sens. 2020, 12, 2008. [CrossRef] 
9. Malhotra, A.; Todd-Brown, K.; Nave, L.E.; Batjes, N.H.; Holmquist, J.R.; Hoyt, A.M.; Iversen, C.M.; Jackson, R.B.; Lajtha, K.; Lawrence, C.; et al. The landscape of soil carbon data: Emerging questions, synergies and databases. Prog. Phys. Geogr. Earth Environ. 2019, 43, 707-719. [CrossRef]

10. Vasques, G.M.; Grunwald, S.; Sickman, J.O. Modeling of soil organic carbon fractions using visible-near infrared spectroscopy. Soil Sci. Soc. Am. J. 2009, 73, 176-184. [CrossRef]

11. Sarkhot, D.V.; Grunwald, S.; Ge, Y.; Morgan, C.L.S. Comparison and detection of total and available soil carbon fractions using visible/near infrared diffuse reflectance spectroscopy. Geoderma 2011, 164, 22-32. [CrossRef]

12. Moura-Bueno, J.M.; Dalmolin, R.S.D.; Ten Caten, A.; Dotto, A.C.; Demattê, J.A. Stratification of a local VIS-NIR-SWIR spectral library by homogeneity criteria yields more accurate soil organic carbon predictions. Geoderma 2019, 337, 565-581. [CrossRef]

13. Šestak, I.; Mihaljevski Boltek, L.; Mesić, M.; Zgorelec, Ž.; Perčin, A. Hyperspectral sensing of soil pH, total carbon and total nitrogen content based on linear and non-linear calibration methods. J. Cent. Eur. Agric. 2019, 20, 504-523. [CrossRef]

14. Viscarra Rossel, R.A.; Hicks, W.S. Soil organic carbon and its fractions estimated by visible-near infrared transfer functions. Eur. J. Soil Sci. 2015, 66, 438-450. [CrossRef]

15. Fortuna, A.M.; Starks, P.J.; Nelson, A.M.; Steiner, J.L. Prediction of Soil Carbon Fractions Using a Field Spectroradiometer Equipped with an Illuminating Contact Probe. Soil Syst. 2019, 3, 71. [CrossRef]

16. Stenberg, B.; Rossel, R.A.V.; Mouazen, A.M.; Wetterlind, J. Visible and near infrared spectroscopy in soil science. Adv. Agron. 2010, 107, 163-215. [CrossRef]

17. Thaler, E.A.; Larsen, I.J.; Yu, Q. A new index for remote sensing of soil organic carbon based solely on visible wavelengths. Soil Sci. Soc. Am. J. 2019, 83, 1443-1450. [CrossRef]

18. Aldana-Jague, E.; Heckrath, G.; Macdonald, A.; Van Wesemael, B.; Van Oost, K. UAS-based soil carbon mapping using VIS-NIR (480-1000) mult-spectral imaging: Potential and limitations. Geoderma 2016, 275, 55-66. [CrossRef]

19. Crucil, G.; Castaldi, F.; Aldana-Jague, E.; Van Wesemael, B.; Macdonald, A.; Van Oost, K. Assessing the performance of UAS-compatible multispectral sensors for soil organic carbon prediction. Sustainability 2019, 11, 1889. [CrossRef]

20. Nelson, D.W.; Sommers, L. Total carbon, organic carbon, and organic matter. Methods Soil Anal. Part 2 Chem. Microbiol. Prop. 1983, 9, 539-579.

21. Paul, E.A.; Morris, S.J.; Böhm, J.S.; Lal, R. (Eds.) The determination of soil C pool sizes and turnover rates: Biophysical fractionation and tracers. In Assessment Methods for Soil Carbon; Advances in Soil Science; CRC Press: Boca Raton, FL, USA, 2001; pp. 193-206.

22. Carter, M.R.; Gregorich, E.G. Soil Sampling and Methods of Analysis; CRC Press: Boca Raton, FL, USA, 2007.

23. Bellon-Maurel, V.; Fernandez-Ahumada, E.; Palago, B.; Roger, J.M.; McBratney, A. Critical review of chemometric indicators commonly used for assessing the quality of the prediction of soil attributes by NIR spectroscopy. Trends Anal. Chem. 2010, 29, 1073-1081. [CrossRef]

24. Chang, C.W.; Laird, D.A.; Mausbach, M.J.; Hurburgh, C.R. Near-infrared reflectance spectroscopy-principal components regression analyses of soil properties. Soil Sci. Soc. Am. J. 2001, 65, 480-490. [CrossRef]

25. Ludwig, B.; Khanna, P.K.; Bauhus, J.; Hopmans, P. Near infrared spectroscopy of forest soils to determine chemical and biological properties related to soil sustainability. For. Ecol. Manag. 2002, 171, 121-132. [CrossRef]

26. Fang, Q.; Hong, H.; Zhao, L.; Kukolich, S.; Yin, K.; Wang, C. Visible and near-infrared reflectance spectroscopy for investigating soil mineralogy: A review. J. Spectrosc. 2018, 2018, 3168974. [CrossRef]

27. Ben-Dor, E.; Inbar, Y.; Chen, Y. The reflectance spectra of organic matter in the visible near-infrared and short wave infrared region (400-2500 nm) during a controlled decomposition process. Remote Sens. Environ. 1997, 61, 1-15. [CrossRef]

28. Rossel, R.V.; Walvoort, D.J.J.; McBratney, A.B.; Janik, L.J.; Skjemstad, J.O. Visible, near infrared, mid infrared or combined diffuse reflectance spectroscopy for simultaneous assessment of various soil properties. Geoderma 2006, 131, 59-75. [CrossRef]

29. Kimsey, M.J.; Laing, L.E.; Anderson, S.M.; Bruggink, J.; Campbell, S.; Diamond, D.; Domke, G.M.; Gries, J.; Holub, S.M.; Nowacki, G.; et al. Soil Mapping, Monitoring, and Assessment. In Forest and Rangeland Soils of the United States Under Changing Conditions; Springer: Cham, Switzerland, 2020; pp. 169-188.

30. Thompson, J.A.; Kienast-Brown, S.; D'Avello, T.; Philippe, J.; Brungard, C. Soils2026 and digital soil mapping-A foundation for the future of soils information in the United States. Geoderma Reg. 2020, 22, e00294. [CrossRef]

31. Dangal, S.R.; Sanderman, J.; Wills, S.; Ramirez-Lopez, L. Accurate and precise prediction of soil properties from a large midinfrared spectral library. Soil Syst. 2009, 3, 11. [CrossRef]

32. Dangal, S.R.; Sanderman, J. Is Standardization Necessary for Sharing of a Large Mid-Infrared Soil Spectral Library? Sensors 2020, 20, 6729. [CrossRef] [PubMed]

33. Salley, S.W.; Talbot, C.J.; Brown, J.R. The Natural Resources Conservation Service land resource hierarchy and ecological sites. Soil Sci. Soc. Am. J. 2016, 80, 1-9. [CrossRef]

34. Schnepf and Flanagan. A History of Natural Resource Inventories Conducted by the USDA's Soil Conservation Service and Natural Resources Conservation Service. A Special Report by the Soil and Water Conservation Society. 2016. Available online: https:/ / www.nrcs.usda.gov/Internet/FSE_DOCUMENTS/nrcseprd1212208.pdf (accessed on 29 April 2021).

35. Moriasi, D.N.; King, K.W.; Bosch, D.D.; Bjorneberg, D.L.; Teet, S.; Guzman, J.A.; Williams, M.R. Framework to parameterize and validate APEX to support deployment of the nutrient tracking tool. Agric. Water Manag. 2016, 177, 146-164. [CrossRef] 
36. Bünemann, E.K.; Bongiorno, G.; Bai, Z.; Creamer, R.E.; De Deyn, G.; De Goede, R.; Fleskens, L.; Geissen, V.; Kuyper, T.W.; Mäder, P.; et al. Soil quality-A critical review. Soil Biol. Biochem. 2018, 120, 105-125. [CrossRef]

37. Tavares, T.R.; Molin, J.P.; Nunes, L.C.; Alves, E.E.N.; Melquiades, F.L.; De Carvalho, H.W.P.; Mouazen, A.M. Effect of X-ray tube configuration on measurement of key soil fertility attributes with XRF. Remote Sens. 2020, 12, 963. [CrossRef]

38. Weiss, M.; Jacob, F.; Duveiller, G. Remote sensing for agricultural applications: A meta-review. Remote Sens. Environ. 2020, 236, 111402. [CrossRef] 